\title{
Policy Initiatives in the Global Recession: What Did Forecasters Expect?
}

\author{
Carlos Carvalho, Stefano Eusepi, and Christian Grisse
}

The global recession of 2008-09 led to monetary and fiscal policy responses by central banks and government authorities that were often unconventional in size and scope. A study of expansionary measures employed during the recession suggests that overall, the policies were likely effective in shaping the outlook for a recovery, as forecasters raised their expectations of inflation and GDP growth after the policies' implementation. From this perspective, the policies stimulated economic activity and prevented deflationary pressures during the financial crisis.

$\mathrm{T}$

he global recession of 2008-09 resulted in a significant loss of output (GDP), a large increase in unemployment, and a deflationary scare in many countries. Indeed, forecasters' expectations of inflation and GDP growth deteriorated in fall 2008, particularly after the collapse of Lehman Brothers in September.

The depth, scale, and duration of the recession associated with the financial crisis triggered monetary and fiscal policy responses by central banks and government authorities that in some cases were unconventional in size and scope. Many central banks with policy rates at or near the lower bound of zero percent turned to other stabilization tools, which altered the size and composition of their balance sheets. The Federal Reserve and the Bank of England, for example, implemented large-scale asset purchase programs. In addition, authorities in several countries sought to address the crisis through sizable fiscal stimulus packages involving tax cuts and higher public spending. By spring 2009, inflation and output growth expectations seemed to have stabilized (Chart 1). Stocks and other assets also rebounded around that time (Chart 2).

Assessing the role of monetary and fiscal policies in the stabilization process is a key challenge, and the subject of an intense debate among policymakers, academics, and the public. In this edition of Current Issues, we use cross-country data to investigate the relationship between policies put in place during the global recession and their influence on forecasters' output and inflation expectations. We focus on expectations because they may convey more information about the effectiveness of policies than economic outcomes do. Forecasters adjust expectations quickly after policies are announced; therefore, expectations are less affected by additional changes in economic conditions that could occur once the policies are implemented.

We find that expansionary monetary and fiscal policies, overall, were successful in shaping expectations of a recovery. Forecasters raised their expectations of inflation and GDP growth following implementation of the policies. In particular, monetary expansions appear to have affected inflation forecasts while fiscal policies seem to have influenced expectations of economic growth. From this perspective, the policies 
Chart 1

\section{Consensus Expectations}
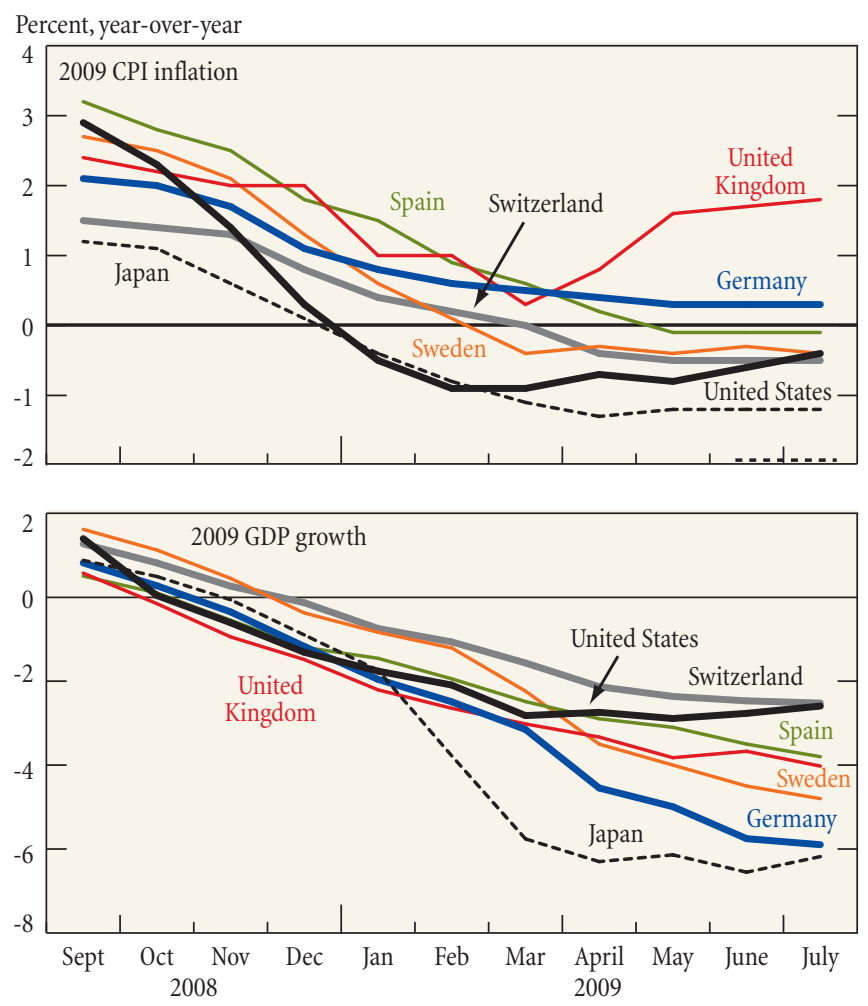

Source: Consensus Economics.

were effective at stimulating economic activity and preventing deflationary pressures during the global recession.

\section{Monetary and Fiscal Responses to Recessions}

The recession of 2008-09 differed from past downturns in several ways. First, it was unusually deep, producing the most severe fall in U.S. output since the Great Depression. Second, it was a global recession, affecting not only the United States but most developed and emerging economies. Third, it was associated with a financial crisis that led to unusual uncertainty about the economic outlook; past financial crises have normally been associated with prolonged economic downturns and slower recoveries.

In typical recessions, central banks respond through monetary policy actions, for example, by lowering interest rates; fiscal policy relies on automatic stabilizers (fiscal deficits automatically increase as tax revenues fall and social safety net outlays, such as unemployment insurance payments, rise). In contrast, the severity of the recent financial crisis required these conventional responses to be complemented by more aggressive measures, such as the expansion of central bank balance sheets and the use of large fiscal stimulus packages. In this section, we briefly review the rationale for the monetary and fiscal policies put in place in response
Chart 2

\section{Rebound in Global Stock Markets}

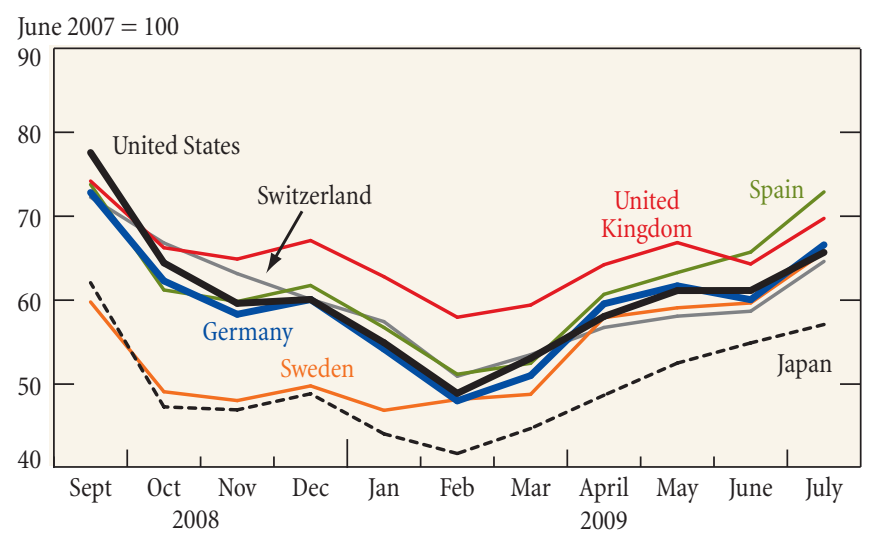

Source: Haver Analytics.

to the recession and the potential transmission mechanisms between the policies and forecasters' expectations of output and inflation.

\section{Central Bank Balance Sheet Expansions}

The increases in central bank balance sheets observed during the crisis reflect a variety of policy measures with different aims and transmission mechanisms. A useful classification of alternative forms of balance sheet policies ${ }^{1}$ makes a distinction between:

1) exchange rate-related policy, designed to affect the level and volatility of the exchange rate; 2 ) quasi-debt-management policy, intended to lower borrowing costs and raise asset prices; 3) credit policy, designed to improve financing conditions in specific private sector debt markets; and 4) bank reserves policy, aimed at boosting lending and stimulating aggregate demand. The size of the balance sheet is not only a by-product of the first three policies, but also a direct objective of bank reserves policy.

\section{Exchange Rate-Related Policy}

Some policies, such as those implemented by the Swiss National Bank and the Bank of Israel, focused on the foreign exchange market. To prevent excessive currency appreciation, central banks can purchase foreign currency, which also increases the size of their balance sheet. By limiting currency appreciation or generating currency depreciation, such interventions should boost demand for exports and prevent inflation from falling.

\section{Quasi-Debt-Management Policy and Credit Policy}

Some measures were designed to lower borrowing costs; two of these are quasi-debt-management policy and credit policy. For example, one policy measure behind the large increase in balance sheets during the crisis was asset purchases by central

\footnotetext{
${ }^{1}$ See Borio and Disyatat (2010).
} 
banks, such as the Federal Reserve's large-scale purchases or the Bank of England's "quantitative easing" purchase program. Asset purchases may raise asset prices through the so-called "portfolio balance effect": for instance, purchases of private sector assets, by increasing demand for them, raise asset prices and improve liquidity conditions. Higher asset prices imply greater wealth for those who hold the assets and lower borrowing costs for consumers and firms. This stimulates aggregate demand, which in turn tends to put upward pressure on prices. (For further details, see Joyce, Tong, and Woods [2011], who describe the quantitative easing policy implemented by the Bank of England.)

\section{Bank Reserves Policy}

The size of central bank balance sheets can also have a direct effect on aggregate demand. As an example, consider the policy of quantitative easing pursued by the Bank of England. The Bank bought financial assets (overwhelmingly government debt) with the aim of "boosting the supply of money and credit and thus raising the rate of growth of nominal spending to a level consistent with meeting the inflation target in the medium term." 2 Quantitative easing is designed to affect output growth and inflation via two distinct channels: through its effect on asset prices and through its effect on the supply of credit. ${ }^{3}$ Asset purchases, by exchanging assets with reserves, increase the amount of funds available to financial institutions and should lead to greater lending. Through both channels, aggregate spending increases: Consumers and firms are likely to spend more if their wealth increases, if it is easier for them to obtain loans, and if they hold more money in their accounts. Finally, higher spending also places upward pressure on prices and wages, thus raising inflation.

\section{Fiscal Stimulus}

The fiscal stimulus packages implemented during the recession of 2008-09 included a mix of government spending increases and tax cuts. Both measures were designed to stabilize economic activity and inflation by stimulating aggregate spending.

An increase in government spending has a direct effect on the economy by inducing higher demand for goods and services. The resulting rise in income and employment also provides an indirect effect by stimulating higher private consumption, as households and firms gain more purchasing power. While the size of this "fiscal multiplier" is the subject of strong debate among policymakers and academics, there is agreement on the fact that it depends on both the current state of the economy and the stance of monetary policy. If an economy is growing at close to its full potential and inflation is near the desired level, an increase in government spending produces excess aggregate demand, putting upward pressure on wages and prices. If, in response, the central bank hikes interest rates, raising the cost of borrowing for households and firms, then

\footnotetext{
${ }^{2}$ http://www.bankofengland.co.uk/publications/news/2009/019.htm.

${ }^{3}$ http://www.bankofengland.co.uk/monetarypolicy/pdf/qe-pamphlet.pdf.
}

higher demand from expansionary fiscal policy is partly offset by lower private spending, dampening the expansionary effects of the fiscal stimulus. If an economy is in a recession, with low resource utilization and with inflation below the level consistent with the central bank's mandate, an increase in government spending has the appealing feature of boosting both aggregate demand and inflation. Under these circumstances, the central bank is likely to keep interest rates low or stable until the recovery begins, thus preventing the crowding out that would otherwise reduce the fiscal multiplier. When central banks lower rates to or close to the "zero lower bound" in a deep recession, market participants might expect the effects of fiscal stimulus to be large.

Unlike higher government spending, lower taxes imply more disposable income for households and firms. Some or all of this increase in disposable income is usually saved. Economic theory suggests that a considerable fraction of a tax cut may be saved, as households recognize their need to pay for future tax increases in times of fiscal consolidation. Empirical evidence also suggests that increases in government spending have stronger effects on the economy than tax cuts do. However, during a financial crisis, many households and firms may face rising costs of borrowing and diminished access to credit markets because their private wealth has been reduced. Here, a tax cut can restore the ability to spend and should therefore have more stimulative effects on aggregate spending as well as contribute to upward pressure on inflation. ${ }^{4}$

\section{Evaluating the Expected Effects of Policies during the Great Recession}

To the extent that monetary and fiscal policies are viewed as expansionary, they should have an immediate impact on expectations. Economic theory also assigns a key role to expectations in the policy transmission mechanism. For example, increased optimism about future economic growth is likely to stimulate spending by households and firms today. Also, higher inflation expectations may reduce the real cost of borrowing for households and firms, and thus boost economic activity.

Several studies have looked at the effect of policy interventions on financial markets during the crisis, focusing mainly on liquidity facilities and asset purchases introduced by central banks in 2008-09. To distinguish movements in asset prices attributable to changes in policy from movements caused by other factors, one strand of the literature has employed the event-study methodology, examining changes in asset prices during a narrow time window around the policy announcement or the actual policy intervention. ${ }^{5}$ The underlying assumption used to identify the effect of policy is that, during this short window - typically ranging from a few minutes to a few days-

\footnotetext{
${ }^{4}$ Parker et al. (2011) provide evidence that economic stimulus payments disbursed in 2008 by the U.S. government had substantial effects on spending, in particular for lower-income, older, and home-owning households.

${ }^{5}$ See, for example, Gagnon et al. (2010), Neely (2010), Aït-Sahalia et al. (2009), and Joyce et al. (2010).
} 
any changes in financial markets will solely reflect the impact of the policy announcement, because the economic environment is otherwise unchanged. Other studies have focused on the effect of policy interventions on financial markets over a longer period. ${ }^{6}$ Recent studies by Baumeister and Benati (2010) and Cúrdia and Ferrero (2011) analyze the effects of a policy-induced reduction in long-term bond yields on economic activity and inflation. While Baumeister and Benati find large effects for the United States, Japan, and the euro area, Cúrdia and Ferrero, focusing only on the United States, find positive but small effects.

We take a different approach. First, recall that we assess the potential effects of policies on expectations of inflation and output growth rather than on financial variables or realized measures of economic activity and inflation. We use data on a crosssection of countries to evaluate these policy effects. And our methodology exploits differences in the evolution of expectations across countries that are associated with differences in policy. ${ }^{7}$ As an example, consider an expansion in central bank balance sheets during the crisis: if stronger balance sheet growth-corresponding to looser monetary policy_increased expectations of future inflation, then one should expect countries with higher balance sheet expansions on average to experience larger increases (or smaller decreases) in inflation expectations.

\section{Measures of Inflation and Output Growth Expectations} To measure expectations of inflation and output growth, we use data from Consensus Economics, a firm that conducts international economic surveys. Each month, Consensus Economics collects forecasts for a set of macroeconomic and financial variables for advanced economies and selected emerging economies from a range of financial analysts. The forecasts are for year-over-year growth rates in the consumer price index and in real GDP. ${ }^{8}$ From this data set, we use the mean of analysts' forecasts of inflation and GDP growth. Our sample includes the Group of Twenty (G-20) economies except for Indonesia and the euro-area countries except for Cyprus, Luxembourg, Malta, Slovakia, and Slovenia. ${ }^{9}$ To broaden the data set, we also include Denmark, Hungary, Israel, New Zealand, Norway, Sweden, Switzerland, and Thailand.

\section{A Measure of Unconventional Monetary Policy}

The growth of selected central bank balance sheets during the Great Recession can be seen in Chart 3. Balance sheet expansions after September 2008 were in many cases a direct response to

\footnotetext{
${ }^{6}$ See, for example, Frank and Hesse (2009), Stroebel and Taylor (2009), Taylor and Williams (2009), D’Amico and King (2010), Gagnon et al. (2010), and Hamilton and $\mathrm{Wu}(2012)$.

${ }^{7}$ However, we emphasize that this type of analysis is subject to well-known limitations, which we discuss subsequently.

${ }^{8}$ Exceptions are Argentina, Brazil, Mexico, and Russia, where inflation forecasts are for December/December. For India, the forecasts are for average inflation and growth over the fiscal year, which begins on April 1.

${ }^{9}$ No central bank balance sheet data were available for Indonesia; the other five countries were excluded because of data limitations.
}

\section{Chart 3 \\ Evolution of Central Bank Balance Sheets during the Great Recession}

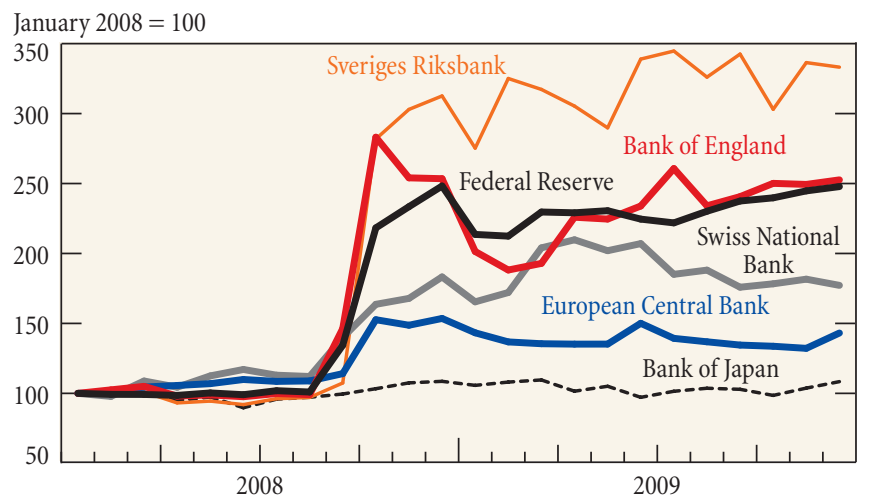

Sources: Haver Analytics; authors' calculations.

the escalation of the financial crisis after the failure of Lehman Brothers. Around that time, several central banks introduced new credit facilities to provide the financial sector with unprecedented access to liquidity. Starting in early spring 2009, an additional, steadier increase occurred in the size of balance sheets, typically attributable to new or expanded asset purchase programs.

Our analysis of unconventional policy actions focuses on the February-December 2009 period. The period represents a compromise between use of a narrow window around March 2009, when expectations appear to have stabilized (see Chart 1), and a window that is sufficiently long to cover increases in asset purchase programs that occurred throughout 2009 but were already announced or anticipated earlier. ${ }^{10}$ Moreover, March 2009 coincides with the introduction or extension by central banks of major asset purchase programs. For example, while the Federal Reserve initially announced that it would purchase up to $\$ 100$ billion of agency debt and up to $\$ 500$ billion of mortgage-backed securities (MBS) in November 2008, it expanded its large-scale asset purchases significantly in March 2009, with purchases still taking place at the end of 2009. The Bank of England began its asset purchase program financed by the creation of central bank reserves (quantitative easing) in March 2009. ${ }^{11}$ Also, the expanded balance sheet of the Swiss National Bank during the crisis partly reflects the Bank's purchases of foreign currency, initiated in March 2009, to prevent further appreciation of the Swiss franc in

\footnotetext{
${ }^{10}$ As we explain below, the key results of our analysis are robust to changes in the time window over which central bank balance sheet expansions are measured.

${ }^{11}$ In March 2009, the Federal Reserve announced that it would increase its MBS purchases by $\$ 750$ billion as well as purchase additional agency debt and begin purchasing long-term U.S. government debt. The Bank of England initially announced asset purchases worth $£ 75$ billion in March 2009 and increased that amount to $£ 200$ billion by November (asset purchases were completed in January 2010).
} 
the face of safe-haven flows. ${ }^{12}$ Similarly, the gradual expansion of the Bank of Israel's balance sheet over the 2008-09 period reflects the Bank's foreign exchange interventions.

Monetary authorities in some of our sample countries had been experiencing strong balance sheet expansions for a few years prior to the 2008-09 recession, likely as a by-product of their monetary and exchange rate arrangements. Therefore, to measure the extent to which expansions during the crisis were "unconventional," we consider deviations from average rates of balance sheet expansion calculated in a precrisis period. We refer to such deviations as "detrended balance sheet growth." Concretely, for each monetary authority, we calculate "average growth" as the annual rate of balance sheet expansion between January 2005 and June 2007. We then subtract ten months of "average growth" from the February-December 2009 balance sheet change. For euro-area countries, we use the detrended balance sheet growth of the Eurosystem, since monetary decisions are made centrally by the European Central Bank (ECB).

\section{Measuring Fiscal Expansions during the Crisis}

In 2008-09, faced with a collapse in economic activity and rising unemployment, most governments in our sample countries introduced fiscal stimulus packages to boost their economies. The data we use to study these efforts combine information from Prasad and Sorkin (2009) with announcements made by national authorities in late 2008 through April 2009. Stimulus packages averaged slightly less than 3 percent of GDP in these countries. However, there was considerable variation in size, with the bottom quarter of countries implementing packages with an average size of 1 percent of GDP and the top quarter enacting packages reaching about 4 percent.

Of note, our measure of fiscal stimulus does not distinguish between tax cuts and spending increases. Most countries implemented a mix of government spending and tax cuts. Prasad and Sorkin (2009) find that among G-20 countries, the share of tax cuts was about 30 percent of total stimulus, but again there is considerable variation across countries. For example, they report that in the United States the share of tax cuts was about 45 percent, while countries like the United Kingdom and Brazil relied almost exclusively on them. In contrast, China relied largely on increased government spending.

\section{Balance Sheet Expansions and Changes in Expectations} We now consider the relationship between central bank balance sheet expansions and changes in forecasters' expectations for

\footnotetext{
12 The Swiss National Bank announced in March 2009 that it would begin to intervene in the currency market to prevent a further appreciation of the Swiss franc against the euro. This intervention, which continued into 2010, was only partially sterilized. In addition, the Swiss National Bank purchased bonds issued by the private sector and lowered its target range for the three-month Libor (London interbank offered rate) to 0-0.75 percent, aiming for the lower end of the target band.
}

Chart 4

\section{Reversal in 2009 Inflation Expectations}

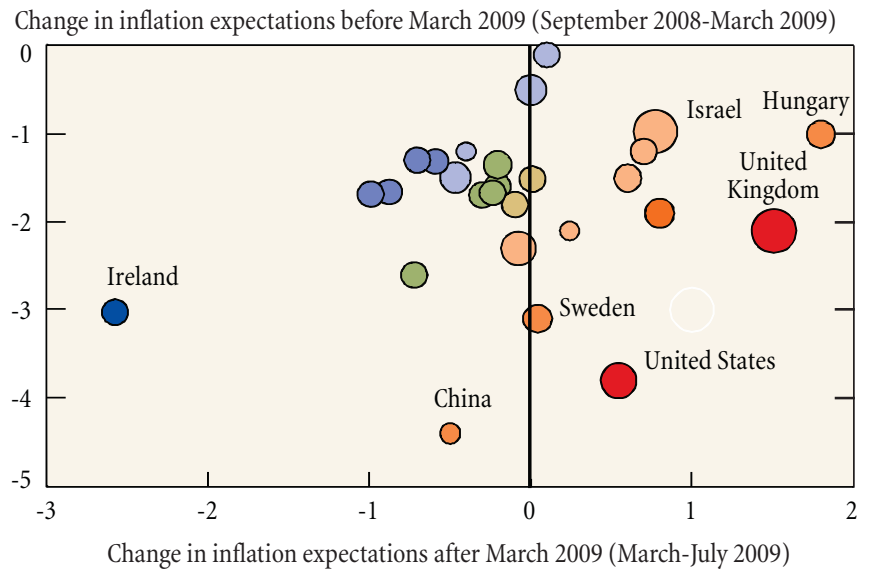

Source: Authors' calculations, using data from Consensus Economics and national central banks.

Note: The size of each data point reflects the percentage change in the detrended balance sheet, February-December 2009.

2009 inflation (Chart 4). Each data point represents a country, with the size reflecting the size of the (detrended) central bank balance sheet increase from February to December 2009. ${ }^{13}$ The chart plots the change in inflation expectations between September 2008 - the month of the Lehman bankruptcy — and March 2009 on the vertical axis and the change in expectations between March 2009 and July 2009 on the horizontal axis. We choose these dates because September 2008-March 2009 roughly corresponds to the period when expectations of inflation and growth declined dramatically, while expectations stabilized/rebounded afterward (see Chart 1). We also focus on March 2009 as a breakpoint because it roughly corresponds to the introduction of several asset purchase programs implemented by central banks. The choice of July 2009 for the end of the time window allows us to capture the changes in expectations that we are trying to explain while keeping the window relatively narrow. The results using windows ending in adjacent months are broadly consistent with the findings we report below.

Movements from the upper-left to lower-right regions of Chart 4 are associated with countries experiencing larger expectations reversals - that is, larger declines before March 2009 and/or larger increases after March 2009, with larger reversals depicted by "warmer" colors (from dark to light blue, light red, and dark red). For example, while Ireland and Sweden experienced a similar 3 percentage point decline in inflation expectations leading up to March 2009, in spring 2009 expectations

\footnotetext{
${ }^{13}$ The size of the data points is equal to a constant plus the size of the detrended balance sheet expansion (note that several central banks experience a balance sheet decline between February and December 2009 once we subtract trend growth). We add a constant so all data points are visible.
} 
stabilized in Sweden but continued to deteriorate in Ireland. What emerges from the chart is the observation that countries implementing larger central bank balance sheet expansions between February and December 2009 tended to also experience greater expectations reversals: larger declines before March 2009 and/or larger increases after March 2009. That is, the bigger circles in the chart tend to be associated with the "warmer" colors. We caution, however, that while the chart suggests a relationship between balance sheet expansions and changes in expectations, it does not necessarily mean that the former leads to the latter.

\section{Estimation Results}

To investigate further the relationship between balance sheet expansions and changes in expectations, we run cross-country regressions of changes in expectations of inflation and GDP growth between March and July 2009 on measures of detrended central bank balance sheet growth and fiscal expansions (see Model 1 in the box). From the discussion above, we should expect both monetary and fiscal stimulus variables to increase expected output growth and inflation.

Note that the size of the coefficients on fiscal stimulus is not directly comparable to the estimates of fiscal multipliers discussed in the academic and policy debate. Recall that we look at the effect of fiscal expansions on expectations of economic growth rather than on economic outcomes. Also, we do not distinguish between fiscal expansions consisting of tax cuts or spending increases, actions that could potentially have different effects on economic activity.

Table 1 summarizes the regression results for Model 1. Detrended balance sheet expansions are associated with higher consensus expectations of 2009 and 2010 inflation. Quantitatively, our results suggest that a balance sheet expansion of 10 percent above trend is associated with an 18.2 basis point increase in consensus expectations of 2009 inflation and a 7.8 basis point increase in consensus expectations of 2010 inflation. Fiscal stimulus appears to have no significant association with inflation expectations. In contrast, it is associated with expectations of higher growth for 2009, although the coefficient is not significant for expectations of 2010 growth. For 2009, our results suggest that a fiscal stimulus of 1 percent of GDP is associated with higher expected growth of 0.12 percentage point. The results from this first regression are consistent with the view that balance sheet expansions have a significant effect on inflation expectations, while fiscal stimulus packages are associated with an increase in short-term growth expectations. These results suggest that a combination of monetary and fiscal stimulus would be needed to bring inflation and growth expectations closer to desired levels.

Table 2 presents the results of a new set of regressions that include the decline in expectations prior to March 2009 as an additional control variable on the right-hand side of equation 2 (see Model 2 in the box). There are two important reasons why we control for movements in expectations before March 2009.

\section{Regression Analysis}

To evaluate the relationship between monetary and fiscal stimulus and expectations, we estimate three statistical models. All regressions are estimated using ordinary least squares.

Model 1:

$$
\begin{aligned}
& \Delta^{\text {post }} \pi_{Y, i}^{e}=\beta_{0}^{\pi}+\beta_{1}^{\pi} \text { BalSheetChg }_{i}+\beta_{2}^{\pi} \text { FiscalStimulus }_{i}+\varepsilon_{i}^{\pi} \\
& \Delta^{\text {post } g_{Y, i}^{e}}=\beta_{0}^{g}+\beta_{1}^{g} \text { BalSheetChg }_{i}+\beta_{2}^{g} \text { FiscalStimulus }_{i}+\varepsilon_{i}^{g} .
\end{aligned}
$$

Here, the subscript $i$ represents the country. The variables $\Delta^{\text {post }} \pi_{Y, i}^{e}$ and $\Delta^{\text {post }} g_{Y, i}^{e}$ denote changes in expectations of inflation and growth in a given year $Y$; in particular, $\Delta^{\text {post }}$ represents the change between March and July 2009 in the benchmark specification. BalSheetChg $g_{i}$ and FiscalStimulus ${ }_{i}$ denote above-trend growth in the central bank's balance sheet and fiscal stimulus. The coefficient $\beta_{1}^{\pi}$ measures the percentage change in inflation expectations associated with a 1 percent change in the balance sheet size relative to its trend. Similarly, the coefficient $\beta_{2}^{\pi}$ measures the change in inflation expectations (in basis points) associated with a 1 percent change in the fiscal stimulus package expressed as a fraction of GDP.

We also estimate an alternative version of Model 1, augmented with an additional variable.

Model 2:

$$
\begin{aligned}
\Delta^{\text {post }} \pi_{Y, i}^{e}= & \beta_{0}^{\pi}+\beta_{1}^{\pi} \text { BalSheetCh }_{i}+\beta_{2}^{\pi} \text { FiscalStimulus }_{i} \\
& +\beta_{3}^{\pi} \Delta^{\text {pre }} \pi_{Y, i}^{e}+\varepsilon_{i}^{\pi} \\
\Delta^{\text {post }} g_{Y, i}^{e}= & \beta_{0}^{g}+\beta_{1}^{g} \text { BalSheetChg }_{i}+\beta_{2}^{g} \text { FiscalStimulus }_{i} \\
& +\beta_{3}^{g} \Delta^{\text {pre }} g_{Y, i}^{e}+\varepsilon_{i}^{g},
\end{aligned}
$$

where $\Delta^{\text {pre }}$ denotes the change in the relevant variable between September 2008 - the month of the Lehman bankruptcy — and March 2009. The additional variables $\Delta^{p r e} \pi_{Y, i}^{e}$ and $\Delta^{p r e} g_{Y, i}^{e}$ control for the degree to which expectations declined before March 2009. The coefficients associated with the second regression model have the same interpretation as in Model 1. Model 2 formalizes the relationship between policies and expectations reversals suggested in the text by Chart 4 . It allows us to evaluate the change in expectations associated with a change in policies implemented around March 2009, controlling for any change in expectations before March 2009-that is, controlling for $\Delta^{p r e} \pi_{Y, i}^{e}\left(\right.$ or $\left.\Delta^{p r e} g_{Y, i}^{e}\right)$ in the regression.

In a third step, we allow for a differential impact of fiscal policy when short-term interest rates are at the lower bound. Let $L B_{i}$ denote a variable that equals 1 if the policy rate is at the zero lower bound, and 0 otherwise. And similarly, let $N B L_{i}=1-L B_{i}$ denote a variable that equals 1 if the policy rate is not at the lower bound, and 0 otherwise. Then we estimate

Model 3:

$$
\begin{aligned}
\Delta^{\text {post }} \pi_{Y, i}^{e}= & \beta_{0}^{\pi}+\beta_{1}^{\pi} \text { BalSheetChg }_{i}+\left(\beta_{2, L B}^{\pi} L B_{i}+\beta_{2, N L B}^{\pi} N B L_{i}\right) \\
& \text { FiscalStimulus }_{i}+\varepsilon_{i}^{\pi} \\
\Delta^{\text {post } g_{Y, i}^{e}=} & \beta_{0}^{g}+\beta_{1}^{g} \text { BalSheetChg }_{i}+\left(\beta_{2, L B}^{g} L B_{i}+\beta_{2, N L B}^{g} N L B_{i}\right) \\
& \text { FiscalStimulus } s_{i}+\varepsilon_{i}^{g} .
\end{aligned}
$$

Here, coefficients with the subscript $L B$ capture the relationship with fiscal stimulus when the policy rate is at the lower bound. 


\begin{tabular}{lcccccc} 
& \multicolumn{2}{c}{2009} & & \multicolumn{2}{c}{2010} \\
\cline { 2 - 3 } \cline { 5 - 6 } Dependent Variables & Inflation & Growth & & Inflation & Growth \\
\hline Constant & .06 & $-1.63^{* * *}$ & & -.09 & $-.33^{* *}$ \\
& $(.15)$ & $(.27)$ & & $(.10)$ & $(.13)$ \\
Balance sheet & {$[.70]$} & {$[.00]$} & & {$[.37]$} & {$[.02]$} \\
& $1.82^{* *}$ & 1.50 & & $.78^{* *}$ & .18 \\
\hline Fiscal stimulus & $(.75)$ & $(1.42)$ & & $(.32)$ & $(.42)$ \\
& {$[.02]$} & {$[.30]$} & & {$[.02]$} & {$[.67]$} \\
& -3.46 & $12.04^{*}$ & & -1.08 & 3.12 \\
\hline$R^{2}$ & $(3.57)$ & $(6.29)$ & & $(2.78)$ & $(3.29)$ \\
\hline Observations & {$[.34]$} & {$[.07]$} & & {$[.70]$} & {$[.35]$} \\
\hline
\end{tabular}

Source: Authors' calculations.

Notes: Parentheses denote Huber-White robust standard errors; brackets denote $p$-values. Dependent variables are the March-July 2009 changes in expectations.

$* * *$ Statistically significant at the 1 percent level.

$* *$ Statistically significant at the 5 percent level.

${ }^{*}$ Statistically significant at the 10 percent level.

First, in late 2008, some countries experienced a more rapid deterioration of expectations of inflation and growth than did others. In these countries, unconventional policies may not have led to an increase in expectations in spring 2009, but may still have succeeded in halting the decline in expectations. As suggested by Chart 4, policy measures can then be considered successful if, for a given decline in expectations before 2009, they are associated with a rebound in expectations.

Second, consider the following alternative explanation for the observed positive relationship between monetary and fiscal stimulus measures and changes in expectations. On the one hand, countries that experienced a larger deterioration in expectations before March 2009 were more likely to adopt these measures. On the other hand, suppose that the change in expectations after March 2009 was related to the degree of deterioration in expectations observed earlier, and would have occurred even in the absence of stimulus packages. Intuitively, one could argue that countries that initially experienced a larger deterioration in expectations were inherently more likely to experience a larger rebound or a stabilization in expectations later-for example, because the extent of the decline in expectations in late 2008 and early 2009 was an overreaction to the escalation of the financial crisis following the Lehman bankruptcy, or because the deterioration and subsequent stabilization of expectations were driven mainly by some other factor. According to this scenario, policy adoption and the rebound in expectations would be statistically related even when monetary and fiscal policies had no effect on
Results: Model 2-Controlling for Change in Expectations before Policy Implementation

\begin{tabular}{lccccc} 
& \multicolumn{2}{c}{2009} & & \multicolumn{2}{c}{2010} \\
\cline { 2 - 3 } \cline { 5 - 6 } Dependent Variables & Inflation & Growth & & Inflation & Growth \\
\hline Constant & 0.28 & -0.75 & & -0.09 & -0.14 \\
& $(0.25)$ & $(0.64)$ & & $(0.1)$ & $(0.17)$ \\
Balance sheet & {$[0.27]$} & {$[0.25]$} & & {$[0.4]$} & {$[0.43]$} \\
& $2.2^{* *}$ & 1.42 & & $0.75^{*}$ & 0.1 \\
& $(0.83)$ & $(1.17)$ & & $(0.42)$ & $(0.51)$ \\
Fiscal stimulus & {$[0.01]$} & {$[0.23]$} & & {$[0.08]$} & {$[0.85]$} \\
& -0.75 & $11.87^{* *}$ & & -1.13 & 3.32 \\
Control variable & $(3.83)$ & $(5.42)$ & & $(3.04)$ & $(3.2)$ \\
& {$[0.85]$} & {$[0.04]$} & & {$[0.71]$} & {$[0.31]$} \\
& 0.15 & 0.21 & & -0.03 & 0.53 \\
\hline$R^{2}$ & $(0.11)$ & $(0.16)$ & & $(0.27)$ & $(0.31)$ \\
\hline Observations & {$[0.21]$} & {$[0.2]$} & & {$[0.92]$} & {$[0.1]$} \\
\hline
\end{tabular}

Source: Authors' calculations.

Notes: Parentheses denote Huber-White robust standard errors; brackets denote $p$-values. Dependent variables are the March-July 2009 changes in expectations. The control variable is the change in expectations for either inflation or output (based on the dependent variable) between September 2008 and March 2009.

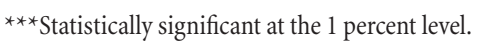

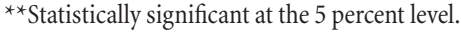

${ }^{*}$ Statistically significant at the 10 percent level.

the economy. By including in the regression a measure of the degree of deterioration in expectations before March 2009, we can evaluate whether for two countries with similar drops in expectations before then, the country that implemented a more aggressive policy response had a larger rebound in expectations.

The estimated coefficients in Table 2 show that our conclusions are unchanged when controlling for changes in expectations before March 2009: Monetary and fiscal stimulus measures implemented in 2008-09 were associated with increases in expectations of output growth and inflation.

\section{The Impact of Fiscal Policy at the Lower Bound}

Recall that the stimulative effects of expansionary fiscal policy may depend on whether policy rates were at the lower bound (Model 3 in the box). To determine which countries' rates were at the lower bound, we look at how policy rates evolved over time. In particular, we assume that for a country to be included in the lower-bound group, the central bank must have left the policy rate unchanged or cut the rate by at most 25 basis points in the March-July 2009 period, and that afterwards the rate must have 
Table 3

\section{Results: Model 3-Fiscal Policy at the Lower Bound}

\begin{tabular}{lccccc} 
& \multicolumn{2}{c}{2009} & & \multicolumn{2}{c}{2010} \\
\cline { 2 - 3 } \cline { 5 - 6 } Dependent Variables & Inflation & Growth & & Inflation & Growth \\
\hline Constant & .05 & $-1.64^{* * *}$ & & -.09 & $-.34^{* *}$ \\
& $(.16)$ & $(.28)$ & & $(.10)$ & $(.14)$ \\
Balance sheet & {$[.74]$} & {$[.00]$} & & {$[.38]$} & {$[.02]$} \\
& $1.59^{*}$ & 1.15 & & $.71^{*}$ & -.29 \\
& $(.87)$ & $(1.68)$ & & $(.36)$ & $(.38)$ \\
\hline Fiscal stimulus NLB & {$[.08]$} & {$[.50]$} & & {$[.06]$} & {$[.46]$} \\
& -5.26 & 9.34 & & -1.63 & -.01 \\
\hline Fiscal stimulus LB & $5.01)$ & $(9.04)$ & & $(3.63)$ & $(.05)$ \\
& {$[.30]$} & {$[.31]$} & & {$[.70]$} & {$[.92]$} \\
\hline$R^{2}$ & 1.31 & $19.21^{* *}$ & & .38 & $12.67^{* * *}$ \\
Observations & $(4.65)$ & $(7.37)$ & & $(2.97)$ & $(2.20)$ \\
\hline & {$[.78]$} & {$[.01]$} & {$[.90]$} & {$[.00]$} \\
\hline
\end{tabular}

Source: Authors' calculations.

Notes: Parentheses denote Huber-White robust standard errors; brackets denote p-values. Dependent variables are the March-July 2009 changes in expectations. The variable "fiscal stimulus LB" captures fiscal stimulus for countries at the lower bound during 2009 according to our criterion (it equals zero for countries not at the lower bound); the variable "fiscal stimulus NLB" includes fiscal stimulus of countries not at the lower bound (it equals zero for countries at the lower bound). The lower-bound group includes Canada, Japan, Switzerland, the United States, and the United Kingdom.

$* * *$ Statistically significant at the 1 percent level.

${ }^{*}$ Statistically significant at the 5 percent level.

* Statistically significant at the 10 percent level.

remained unchanged through the end of 2009. According to this assumption, Canada, Japan, Switzerland, the United States, and the United Kingdom are classified as lower-bound countries. ${ }^{14}$

In line with our previous findings, only central bank balance sheet growth has a significant relationship with inflation expectations (Table 3). In countries where policy rates were at the lower bound, fiscal stimulus is associated with an increase in expectations of GDP growth in 2009 and 2010. The estimated effects are highly significant. In contrast, for countries that are not in the lower-bound group, fiscal expansions are not associated with a statistically significant effect on growth expectations. Quantitatively, the results suggest that for countries whose policy rates were at or close to the lower bound, a fiscal stimulus equal to 1 percent of GDP is associated with a cumulative increase in expectations between March and July 2009 of 0.20 percent for 2009 GDP growth and 0.13 percent for 2010 growth. These results are consistent with the view that fiscal stimulus is more effective when interest rates are at the lower bound.

\footnotetext{
14 The ECB is not classified as belonging to the lower-bound group because it cut its policy rate by 50 basis points between March and May 2009.
}

Interpreting the Results

Our regression results document a relationship between policies implemented and changes in expectations. The key question when interpreting our findings is whether the link between policies implemented during the crisis and the stabilization of inflation and growth expectations observed after March 2009 reflects a causal relationship. First, it is possible that our regressions have omitted variables that drive both changes in expectations and policymakers' decisions to adopt or not adopt specific policies. If this is the case, the estimated effect of policy on changes in expectations may in fact reflect the influence of other factors that are not accounted for in the regressions. Variables that come to mind include economic conditions before the adoption of policies - which we attempted to capture by controlling for the degree of deterioration in expectations before March 2009-and the level of policy rates before the adoption of unconventional monetary policies. ${ }^{15}$

Another potential issue arises because the decision by monetary and fiscal authorities to adopt certain policies is endogenous, that is, it may be directly influenced by the evolution of expectations that we have used as dependent variables in the regressions. If this is true, the estimated coefficients in our regressions will be affected by simultaneous equation bias. However, even if this is the case, the effect of this bias is likely to work against the discovery of a positive link between policy and stabilization in expectations. This is because policymakers arguably would have been less likely to expand the size of their interventions further if they observed a rebound in expectations. Therefore, our results may well understate the true impact of policy interventions during the crisis.

Alternative Measures of Balance Sheet Expansion We chose above-average balance sheet growth as one objective measure of unconventional monetary policy because it is available for a relatively large set of countries. However, it is not immediately clear over which time period balance sheet growth should be measured. In our regression analysis, we measured balance sheet expansions as the change between February and December 2009. This long time period is intended to capture balance sheet expansions that were already announced or anticipated by July 2009 (the end of the period over which changes in expectations are measured). Not all central banks in our sample countries, however, announced specific increases in their balance sheets. Therefore, we consider several alternative specifications for the time window over which balance sheet growth is measured. First, we compute balance sheet growth between February and July 2009 , in line with the measured change in expectations. The estimated regression coefficients under this alternative specification are very similar to our baseline results. Second, for many central

\footnotetext{
15 The results are robust to the inclusion of the level of policy rates in fall 2008 as a control variable in equation 1. Details are available from the authors upon request.
} 
banks, the largest balance sheet expansions occurred in summer/ fall 2008 (Chart 3), in response to the intensified financial market turmoil. These increases occurred before the decline and recovery of expectations that are the focus of this article. It is conceivable, however, that the large interventions in summer 2008 contributed with a delay to the rebound in expectations in March 2009. Accordingly, we consider an alternative measure of balance sheet growth that includes the periods August 2008-December 2009 and August 2008-July 2009.

Using these alternative measures, we find that our results are qualitatively the same and quantitatively very similar to those obtained using our regression analysis reported in Tables 1-3. Furthermore, the results are robust if we use changes in headline balance sheets instead of the detrended measures. In sum, alternative specifications of the balance sheet variable do not affect our main findings. ${ }^{16}$

\section{Conclusion}

Were the expansionary monetary and fiscal policy measures implemented during the financial crisis effective? We find a positive link between the policies and measures of inflation and real GDP growth expectations. After the implementation of various policy initiatives, forecasters raised their expectations of inflation and GDP growth. Their response indicates that the policies were, to some degree, successful in shaping expectations. Our study suggests that both monetary and fiscal stimulus had an impact on expectations, and that the efforts complemented each other. Monetary expansions appear to have had an effect on inflation forecasts while fiscal policies seem to have helped stabilize expectations of economic growth. These policies, however, should not be considered in isolation. For example, countries in which interest rates were close to or at the zero lower bound displayed higher "fiscal multipliers," suggesting that specific monetary and fiscal configurations can have substantially different effects on expectations, depending on each country's unique economic conditions.

\section{References}

Ait-Sahalia, Yacine, Jochen R. Andritzky, Andreas Jobst, Sylwia Barbara Nowak, and Natalia T. Tamirisa. 2009. "How to Stop a Herd of Running Bears? Market Response to Policy Initiatives during the Global Financial Crisis." IMF Working Paper no. 09/204, September.

Baumeister, Christiane, and Luca Benati. 2010. "Unconventional Monetary Policy and the Great Recession: Estimating the Impact of a Compression in the Yield Spread at the Zero Lower Bound.” ECB Working Paper no. 1258, October.

Borio, Claudio, and Piti Disyatat. 2010. “Unconventional Monetary Policies: An Appraisal." The Manchester School 78, no. s1 (September): 53-89.

Cúrdia, Vasco, and Andrea Ferrero. 2011. "How Much Will the Second Round of Large-Scale Asset Purchases Affect Inflation and Unemployment?” Federal Reserve Bank of New York Liberty Street Economics blog, May 4. Available at http://libertystreeteconomics.newyorkfed.org/2011/05/how-much-willthe-second-round-of-large-scale-asset-purchases-affect-inflation-andunemployment.html\#tp.

D’Amico, Stefania, and Thomas B. King. 2010. "Flow and Stock Effects of LargeScale Treasury Purchases." Board of Governors of the Federal Reserve System Finance and Economics Discussion Series, no. 2010-5, September.

Frank, Nathaniel, and Heiko Hesse. 2009. “The Effectiveness of Central Bank Interventions during the First Phase of the Subprime Crisis." IMF Working Paper no. 09/206, September.

Gagnon, Joseph, Matthew Raskin, Julia Remanche, and Brian Sack. 2010. "LargeScale Asset Purchases by the Federal Reserve: Did They Work?” Federal Reserve Bank of New York Staff Reports, no. 441, March.

Hamilton, James D., and Jing (Cynthia) Wu. 2012.“The Effectiveness of Alternative Monetary Policy Tools in a Zero-Lower-Bound Environment." Journal of Money, Credit, and Banking 44, no. s1 (February): 3-46.

Joyce, Michael, Ana Lasaosa, Ibrahim Stevens, and Matthew Tong. 2010. "The Financial Market Impact of Quantitative Easing." Bank of England Working Paper no. 393, July (revised August 2010).

Joyce, Michael, Matthew Tong, and Robert Woods. 2011. “The United Kingdom's Quantitative Easing Policy: Design, Operation, and Impact.” Bank of England Quarterly Bulletin 51, no. 3 (third quarter): 200-12.

Neely, Christopher J. 2010. “The Large-Scale Asset Purchases Had Large International Effects." Federal Reserve Bank of St. Louis Working Paper no. 2010-018c, July (revised January 2011).

Parker, Jonathan A., Nicholas S. Souleles, David S. Johnson, and Robert McClelland. 2011. "Consumer Spending and the Economic Stimulus Payments of 2008." NBER Working Paper no. 16684, January.

Prasad, Eswar, and Isaac Sorkin. 2009. “Assessing the G-20 Stimulus Plans: A Deeper Look." Brookings Institution, March. Available at http://www.brookings .edu/articles/2009/03_g20_stimulus_prasad.aspx.

Stroebel, Johannes C., and John B. Taylor. 2009. "Estimated Impact of the Fed's Mortgage-Backed Securities Purchase Program.” NBER Working Paper no. 15626, December.

Taylor, John B., and John C. Williams. 2009. "A Black Swan in the Money Market." American Economic Journal: Macroeconomics 1, no. 1 (January): 58-83.

\footnotetext{
${ }^{16}$ Details are available from the authors upon request.
} 


\section{ABOUT THE AUTHORS}

Carlos Carvalho is an associate professor of economics at Pontifícia Universidade Católica do Rio de Janeiro; Stefano Eusepi is a senior economist at the Federal Reserve Bank of New York; Christian Grisse is an economist at the Swiss National Bank.

Current Issues in Economics and Finance is published by the Research and Statistics Group of the Federal Reserve Bank of New York. Linda Goldberg, Erica L. Groshen, and Thomas Klitgaard are the editors.

Editorial Staff: Valerie LaPorte, Mike De Mott, Michelle Bailer, Karen Carter, Anna Snider

Production: Carol Perlmutter, David Rosenberg, Jane Urry

Subscriptions to Current Issues are free. Send an e-mail to Research.Publications@ny.frb.org or write to the Publications Function, Federal Reserve Bank of New York, 33 Liberty Street, New York, N.Y. 10045-0001. Back issues of Current Issues are available at http://www.newyorkfed.org/research/current_issues/.

The views expressed in this article are those of the authors and do not necessarily reflect the position of the Federal Reserve Bank of New York, the Federal Reserve System, or the Swiss National Bank.

\section{Follow Us on Twitter!}

The Research Group recently launched a Twitter feed, designed to offer the first word on developments in the Group, such as:

- new publications and blog posts,

- updates on economists' work and speaking engagements,

- postings of key indexes and data,

- media coverage of the Group's work, and

- other news of interest to website visitors.

\section{Follow us: @NYFedResearch}




\section{RELATED READINGS FROM THE FEDERAL RESERVE BANK OF NEW YORK'S RESEARCH GROUP}

\section{Liberty Street Economics Blog Posts}

Forecasting with Internet Search Data

Rebecca Hellerstein and Menno Middeldorp

January 4, 2012

The Failure to Forecast the Great Recession

Simon Potter

November 25, 2011

Can Speculative Trading Magnify Financial

Market Co-movement?

Christian Grisse

September 12, 2011
A Look at the Accuracy of Policy Expectations

Richard Crump, Stefano Eusepi, and Emanuel Moench

August 22, 2011

How Easy Is It to Forecast Commodity Prices?

Jan J. J. Groen and Paolo A. Pesenti

June 27, 2011

Are Rising Commodity Prices Unanchoring

Inflation Expectations?

Robert Rich, Joseph Song, and Joseph Tracy

May 16, 2011

\section{Papers}

Central Bank Transparency, the Accuracy of Professional Forecasts, and Interest Rate Volatility

Menno Middeldorp

Staff Reports, no. 496, May 2011

Central banks worldwide have become more transparent. An important reason is that democratic societies expect more openness from public institutions. Policymakers also see transparency as a way to improve the predictability of monetary policy, thereby lowering interest rate volatility and contributing to economic stability. Most empirical studies support this view. However, there are three reasons why more research is needed. First, some (mostly theoretical) work suggests that transparency has an adverse effect on predictability. Second, empirical studies have mostly focused on average predictability before and after specific reforms in a small set of advanced economies. Third, less is known about the effect on interest rate volatility. To extend the literature, Middeldorp uses the Dincer and Eichengreen transparency index for twenty-four economies of varying income and examines the impact of transparency on both predictability and market volatility. He finds that higher transparency improves the accuracy of interest rate forecasts for three months ahead and reduces rate volatility.

FOMC Communication Policy and the Accuracy of Fed Funds Futures

Menno Middeldorp

Staff Reports, no. 491, April 2011

Over the last two decades, the Federal Open Market Committee (FOMC), the rate-setting body of the United States Federal Reserve System, has become increasingly communicative and transparent. According to policymakers, one of the goals of this shift has been to improve monetary policy predictability. Previous academic research has found that the FOMC has indeed become more predictable. Here, Middeldorp contributes to the literature in two ways. First, instead of simply looking at predictability before and after the Fed's communication reforms in the 1990s, he identifies three distinct periods of reform and measures their separate contributions. Second, he corrects the interest rate forecasts embedded in fed funds futures contracts for risk premiums, in order to obtain a less biased measure of predictability. The author's results suggest that the communication reforms of the early 1990s and the "guidance" provided from 2003 significantly improved predictability, while the release of the FOMC's policy bias in 1999 had no measurable impact. Finally, Middeldorp finds that FOMC speeches and testimonies significantly lower shortterm forecasting errors.

Real-Time Inflation Forecasting in a Changing World Jan J. J. Groen, Richard Paap, and Francesco Ravazzolo Staff Reports, no. 388, August 2009 (revised November 2010)

Groen, Paap, and Ravazzolo revisit inflation forecasting using reduced-form Phillips curve forecasts, that is, inflation forecasts using activity and expectations variables. They propose a model that results from averaging across different regression specifications selected from a set of potential predictors that includes inflation lags, different real activity data, term structure data, nominal data, and surveys. In each of the individual specifications, the authors allow for occasional shocks of random magnitude in the regression parameters. As such, their framework simultaneously addresses structural change and model uncertainty that unavoidably affect Phillips curve forecasts. Over the full 1960-2008 sample, the framework indicates several structural breaks across different combinations of activity measures, which often coincide with, among others, policy regime changes and oil price shocks. The study finds less evidence than elsewhere in the literature for variance breaks and inflation gap persistence. In a real-time, out-of-sample forecasting exercise, the study's model specification generally provides superior onequarter- and one-year-ahead forecasts for quarterly inflation relative to a range of regularly used forecasting models. 